\title{
Identification of community-dwelling older adults at risk of frailty using the PERSSILAA screening pathway: a methodological guide and results of a large-scale deployment in the Netherlands
}

\author{
Stephanie Jansen-Kosterink ${ }^{1,2^{*}}$ (D), Lex van Velsen ${ }^{1,2}$, Sanne Frazer ${ }^{1,2}$, Marit Dekker-van Weering ${ }^{1,2}$, \\ Rónán O'Caoimh ${ }^{4,5}$ and Miriam Vollenbroek-Hutten ${ }^{2,3}$
}

\begin{abstract}
Background: Among community-dwelling older adults, frailty is highly prevalent and recognized as a major public health concern. To prevent frailty it is important to identify those at risk of becoming frail, but at present, no accepted screening procedure is available.

Methods: The screening process developed as part of the PERSSILAA project is a two-step screening pathway. First, older adults are asked to complete a self-screening questionnaire to assess their general health status and their level of decline on physical, cognitive and nutritional domains. Second, older adults who, according to step one, are at risk of becoming frail, are invited for a face-to-face assessment focusing on the domains in depth. We deployed the PERSSILAA screening procedure in primary care in the Netherlands.
\end{abstract}

Results: In total, baseline data were available for 3777 community-dwelling older adults (mean age 69.9 (SD \pm 3.8 )) who completed first step screening. Based on predefined cut-off scores, $16.8 \%$ of the sample were classified as frail ( $n=634), 20.6 \%$ as pre-frail $(n=777)$, and $62.3 \%$ as robust $(n=2353)$. Frail subjects were referred back to their GP without going through the second step. Of the pre-frail older adults, $69.7 \%$ had evidence of functional decline on the physical domain, $67 \%$ were overweight or obese and $31.0 \%$ had evidence of cognitive decline.

Conclusion: Pre-frailty is common among community-dwelling older adults. The PERSSILAA screening approach is a multi-factor, two-step screening process, potentially useful for primary prevention to identify those at risk of frailty and who will benefit most from preventive strategies.

Keywords: Older adults, Primary prevention, Frail, Pre-frail, Screening, Outcome

\section{Background}

Demographic ageing is a global trend. In the European Union, the number of people aged $65+$ will almost double over the next 50 years, from 85 million in 2008 to 151 million in 2060 [1]. Among these older adults,

\footnotetext{
* Correspondence: s.jansen@rrd.nl

${ }^{1}$ Roessingh Research and Development, Roessinghsbleekweg 33b, 7522, AL, Enschede, The Netherlands

${ }^{2}$ University of Twente, Faculty of Electrical Engineering, Mathematics and Computer Science, Telemedicine group, Enschede, the Netherlands Full list of author information is available at the end of the article
}

frailty is highly prevalent; it is also recognized as a major public health concern by the World Health Organization [1]. At the moment, there is, however, no consensus on a definition for frailty [2-4]. Nonetheless, Vellas \& Sourdet, 2017 [5] claim that there is an emerging consensus that preventing frailty in older adults could improve health outcomes and quality of life, and enables a longer period of independent living. In short, it is important to prevent older adults becoming frail $[5,6]$. As preventing frailty starts with identifying older adults at risk of becoming frail (pre-frailty), early screening

(c) The Author(s). 2019 Open Access This article is distributed under the terms of the Creative Commons Attribution 4.0 International License (http://creativecommons.org/licenses/by/4.0/), which permits unrestricted use, distribution, and 
among at risk populations is important [7, 8] and multiple tools are used by clinicians to assess frailty [9]. However, since there is no golden standard [10], the search for the optimal tool continues. An ideal tool to assess those at risk should be easily applicable in daily clinical practice and should be able to assess multiple elements of pre-frailty or frailty including physical, psychological and social domains [11]. It is therefore problematic that most screening instruments only assess the presence of frailty and cannot single out those older adults who are at risk of becoming frail $[12,13]$. This relates to the current lack of a definition of pre-frailty, which is most often defined by cut-offs on frailty screening instruments not reaching the threshold for frailty. Instead, pre-frailty is a complex multi-dimensional risk-state before onset of frailty characterised by pathophysiological changes which can result in poor health outcomes (unpublished systematic review).

In order to intervene promptly, appropriate screening procedures to identify older adults at risk of becoming frail, combined with a set of tailored interventions, are required [14]. The aim of the PERSSILAA (Personalised ICT Supported Service for Independent Living and Active Ageing) project (FP7-ICT-610359) was to develop a community-based, technology-supported health service model that aims to screen older adults for pre-frailty to prevent the development of frailty [15]. As physical and cognitive decline as well as malnutrition, have been identified as major elements of frailty among older adults [16], this project focused on improving these three domains.

The aim of this article is to present the PERSSILAA screening model and the outcome of the screening process. In the Methods section, the two-step PERSSILAA screening pathway will be described in detail including the set-up of population-level (pre)frailty screening in the east of the Netherlands (Twente region). In the Results section, the cross-sectional outcomes of the PERSSILAA screening will be presented including prevalence data and an analysis of the merit of the individual screening instruments that were used to identify (pre) frailty. The Discussion section, finally, will discuss the implications of our work, both in terms of inferences for public health and for population-level screening for frailty.

\section{Methods}

\section{The PERSSILAA screening procedure}

The PERSSILAA screening pathway was a two-step annual screening programme to identify older adults at risk for developing frailty (i.e. pre-frailty). First, older adults were asked to complete a self-screening questionnaire to assess their general health status and their level of decline on physical, cognitive and nutritional frailty domains. Second, older adults who, according to step one, were at risk of developing frailty were invited for a face-to-face assessment that focuses on the physical, cognitive and nutritional domains in more depth.

During the first step, older adults with an age between 65 and 75 years old were asked by their General Practitioner (GP) to complete a comprehensive set of questionnaires including questions on health status and demographic characteristics. This was done via a mass mailing (postal survey) to ensure that all older adults within defined GP practices were reached. These GPs signed up to participate after a general meeting of GPs organized by the municipality. Prior to posting the PERSSILAA screening questionnaire to patients, GPs identified those patients who were, in their opinion, too frail to participate. These patients included those with multiple serious illnesses or those with limited life expectancy monitored extensively by their GP; these did not receive an invitation. Based on the preferences of the older adult, questionnaires can be completed on paper or online. Previous research has shown that offering different types of administration (online or on paper) does not affect screening results $[17,18]$. When the questionnaire was completed online, older adults could receive their results immediately. When the questionnaire was completed on paper, adults could hand over the questionnaire at their GP office or send it by regular mail. Afterwards they received their results via email or by regular mail (when their email address was unknown). Older adults screening as robust were not contacted further; older adults screening positive for pre-frailty were invited for a face-to-face screening (Step two of the PERSSILAA screening); older adults classified as frail, were contacted by their GP $[15,19]$.

During step two of the PERSSILAA screening, a face-to-face assessment was conducted aiming to gain more information on the level of functional decline on physical, cognitive and nutritional domains. During the PERSSILAA project the face-to-face assessments were performed by trained volunteers or students at a location in the older adult's neighbourhood (e.g., a local retirement home). After the face-to-face meeting, older adults received the outcomes of their assessments, information about healthy ageing and advice about the various health programs available in their community. Older adults that were identified as pre-frail on one of the three domains were offered existing training services targeting physical and cognitive domains available in their community organized by their municipality or local welfare organisation, and education about healthy eating for older adults. The service model that accompanies the PERSSILAA screening model was the result of a participatory design process, in which all stakeholders were actively involved. Among other things, it was decided to 
limit the age span of the screening program from 65 to 75 years of age, in order to not interfere with existing screening programs for those over 75 years old and to take advantage of the technology skills of the less old cohort. For more information about the development of the model we refer to Van Velsen et al., 2015 [15].

\section{Instruments including in step one of the PERSSILAA screening pathway}

The initial instrument scored was the Dutch version of the Groningen Frailty Indicator (GFI) $[20,21]$ administered to assess the older adult's general level of frailty. The GFI is a validated 15 -item screening instrument that measures loss of function and resources across physical, cognitive, social and psychological domains. Each item is rated on a 3-point scale (Yes, No, Sometimes). The total score of the Groningen Frailty Indicator has a range from 0 to 15 . A score of 4 or higher represents moderate to severe frailty. The SF-36 [22] physical functioning subscale (PF-10) was then administered to examine perceived physical functioning. The PF-10 consists of 10 items, each rated on a 3-point scale (yes, limited a lot; yes, limited a little; and no, not limited at all). In order to calculate an overall score, all answers are summed and then transformed to a $0-100$ scale. Higher scores represent better health status. Older adults are classified as limited in physical functioning if they score below a cut-off score of 61 (pooled mean score in a general older Dutch population) [23]. The SF-36 PF-10 is validated in Dutch [24]. To screen for cognitive impairment, the self-administered version of the AD8 Dementia Screening Interview (AD8) [25, 26] was used to detect early cognitive changes associated with many common dementing illnesses. Older adults were asked to rate changes in their ability for each of the 8 items, without attributing causality. Each item is rated on a 3-point scale (Yes, a change; No, no change; and Don't know). The final score is a sum of the number items marked "Yes, a change". Based on clinical research findings and validation samples, the following cut points are provided: $0-1$ : Normal cognition and 2 or greater: cognitive impairment is likely to be present. The AD8 is not validated in Dutch. Finally, the Mini Nutrition Assessment Short-Form (MNA-SF) [27] was administered to identify those who were malnourished or at risk of malnutrition. The MNA-SF consist of 6 items, focusing on food intake, weight loss, mobility, psychological stress, neuropsychological problems and Body Mass Index (BMI). By summing up the scores on all 6 items, a total score is derived. A score of 12 to 14 points indicates a normal nutritional status, a score of 8 to 11 points indicates risk of malnutrition and a score of 0 to 7 points indicates that the participant is malnourished. The MNA-SF is validated [28], but not in Dutch.

Based on the GFI, older adults were initially stratified as either robust, pre-frail or frail. GFI scores higher than 4 , were classified as frail; scores of 4 were classified as pre-frail [20]. Older adults were also screened and categorised based on deficits in physical, cognitive and/or nutritional domains identified from the other screening instruments. Older adult were also assigned to the pre-frail group irrespective of their GFI score when they scored 60 or below on the PF-10 items of the SF-36 and / or when they scored 2 or higher on the AD8 and / or if their score on the MNA short form was 7 or lower. Finally, older adults that did not meet at least one of the conditions for being classified as pre-frail or frail were classified as robust. Table 1 provides an overview of the screening questionnaires used during the first step of the PERSSILAA screening procedure and the triage to the three groups.

\section{Instruments including in step two of the PERSSILAA screening pathway}

To assess the physical status of older adults four tests were used. First, the timed up and go (TUG) test [29] was administered. The TUG test is a simple office-based test, used to identify persons at risk of falling because of balance or gait problems. The TUG test is performed 3 times and an average score is calculated. Second, the chair stand test (CST) [30] was administered. The CST tests the level of lower extremity strength. Third, the chair sit and reach test (CSRT) [31] was administered. The CSRT assess the level of physical flexibility. Fourth and finally, the two-minute step test (2MST) [32] was administered. The 2MST tests the level of aerobic endurance. All four objective tests have normal range scores related to gender and age based on previous research [32]. Scoring for TUG test was adapted to the range scores of Rikli \& Jones [32], where an 8-ft TUG

Table 1 Overview of the questionnaires of step one of the PERSSILAA screening and triage to the three groups

\begin{tabular}{lll}
\hline Questionnaire & Domain & Outcome \\
\hline Groningen Frailty Indicator (GFI) [20, 21] & General level of frailty & $4=$ pre-frail \\
& & $\geq 5=$ frail \\
SF-36 [22] physical functioning scale (PF-10) & Physical domain & $\leq 60=$ functional decline/physical pre-frailty \\
The AD8 Dementia Screening Interview (AD8) $[25,26]$ & Cognitive domain & $\geq 2=$ cognitive impairment/cognitive pre-frailty \\
Mini Nutrition Assessment Short-Form (MNA-SF) [27] & Nutritional domain & $\leq 7$ = possible malnutrition/nutritional pre-frailty \\
\hline
\end{tabular}


test was performed instead of $3 \mathrm{~m}$. Scoring of the CSRT is indicated in inches to compare the score with the normal range. Scoring below the pre-defined cut-off scores indicates "functional decline".

For the assessment of the cognitive status, the Quick Mild Cognitive Impairment (Qmci) screen was used. The Qmci screen is a short screening test for cognitive impairment, developed as a rapid, valid and reliable tool for the early detection and differential diagnosis of mild cognitive impairment (MCI) and dementia [33]. The Qmci screen has six subtests covering the following cognitive domains: orientation, working memory (registration), visuospatial/executive function (clock drawing), semantic memory (verbal fluency), and two episodic memory tests (delay recall and logical memory) [34]. Validated in Dutch [35], the Qmci screen can be completed in 3 to $5 \mathrm{~min}$ [34]. The overall Qmci screen score ranges from 0 to 100 , with lower scores indicating cognitive impairment [36].

For the assessment of the nutritional status, the extended form of the Mini Nutrition Assessment (MNA) [27] and waist circumference were used. The extended version of the MNA is a validated screening tool that identifies older adults who are malnourished or at risk for malnutrition. In addition the items of the MNA-SF, the full MNA consists of an extra 12 items to provide additional information. The overall score of the full MNA is calculated by summing the scores on all 18 items.

\section{Ethics}

Considering to Dutch law (Medical Research Involving Human Subjects Act), the nature of this research (general screening of older adults by questionnaire and face-to-face screening) and that public screening initiated by GPs for different health conditions is usual care in the east of the Netherlands, this study did not require formal ethical approval. The appropriate ethics committee (METC Twente) ruled that no formal ethics approval was required in this particular study (K14-42). At the end of the questionnaire, older adults were asked whether they agreed to the use of their data for research purposes, when they agreed they had to tick a checkbox. Only the data from those consenting were included in the PERSSILAA screening database. All data were anonymized.

\section{Statistical analyses}

Statistical analyses were performed with IBM SPSS Statistics 19 for Windows. All outcome measures were visually inspected for normal distribution using histogram and probability plots, prior to the selection of appropriate statistical tests. Descriptive statistical methods were applied for each of the outcome measures. Normal data were presented as mean \pm standard deviation (SD), non-normal as median with range. As the PERSSILAA screening was an annual screening during the length of the PERSSILAA project (three years), only the baseline (first) complete two-step screening data were analyzed and presented in this paper. For statistical analyses, the level of significance was set at $\alpha<0.05$.

\section{Results \\ Demographics}

The PERSSILAA project stated in November 2013 and ended November 2016 and this study was carried out in year two and three of this project. In total, 32 GP offices participated and 10,331 community-dwelling older adults were invited to participate in the first step of the PERSSILAA screening. With a response rate of $36.6 \%$, the data of 3777 of the older adults were stored in the PERSSILAA screening database. The demographic characteristics of the 3777 older adults included in this analysis are presented in Table 2 . The mean age of the older adults was 69.9 (SD \pm 3.8 ). The majority of those participating had access to the internet, and $30 \%$ of the older adults completed the questionnaire online.

\section{Results of step one of the PERSSILAA screening}

Based on the first step of the PERSSILAA screening, $16.8 \%$ of the older adults were classified as frail $(n=$ $634), 20.6 \%$ of the older adults were classified as pre-frail ( $n=777$ ), and $62.3 \%$ of the older adults were classified as robust $(n=2353)$. The results of 13 participants were incomplete. Table 3 provides an overview of the average score on each measurement instrument according to the classification of the participants. Among the older adults identified as frail, $11.3 \%$ showed impairments in all three domains, $24.6 \%$ had decline on two of the three domains (16.9\% in the physical and cognitive domains, $4.8 \%$ in the physical and nutritional domains and $2.9 \%$ on the cognitive and nutritional domains), and 36.8\% experienced problems in only one domain $(21.7 \%$ in the physical domain, $11.1 \%$ in the cognitive domain, $4.0 \%$ in the nutritional domain). Among those identified as pre-frail, $0.8 \%$ showed impairment in all three domains, $10.5 \%$ in two of the three $(7.8 \%$ in the physical and cognitive domains, $2.2 \%$ in the physical and nutritional domains, and $0.5 \%$ in the cognitive and nutritional domains), and $68.3 \%$ experienced decline in only one domain $(39.7 \%$ in the physical domain, $25.6 \%$ in the cognitive domain, $3.0 \%$ in the nutritional domain).

\section{Results of step two of the PERSSILAA screening}

In total, 623 older adults marked as pre-frail accepted the invitation for step two of the PERSSILAA screening. Table 4 presents the outcomes of the second set of assessments for the physical domain. Based on these 
Table 2 Demographic characteristics of the baseline PERSSILAA screening sample $(n=3777)$

\begin{tabular}{ll}
\hline Gender (Percentage) & $48.3 \%$ male \\
& $51.7 \%$ female \\
$\begin{array}{l}\text { Age (Mean years and Standard } \\
\text { deviation, SD) }\end{array}$ & 69.9 (SD \pm 3.8$)$ \\
$\begin{array}{l}\text { Body Mass Index (Mean and } \\
\text { standard deviation, SD) }\end{array}$ & $27.2(\mathrm{SD} \pm 4.7)$ \\
Level of Education (Percentage) & $1.8 \%$ No qualification \\
& $9.9 \%$ Primary school \\
& $17.9 \%$ Secondary school \\
& $22.6 \%$ Vocational school \\
& for $2-3$ years \\
& $25.3 \%$ High school \\
& $18.2 \%$ Bachelor's degree \\
& $4.3 \%$ University / PhD \\
& $20.9 \%$ alone \\
Living situation (Percentage) & $79.1 \%$ with someone else \\
Number of cigarettes (Mean years & $88.3 \%$ yes \\
Internet access (Percentage) & $11.7 \%$ no \\
Alcohol - daily intake (Percentage) & $51.3 \%$ yes \\
& $48.7 \%$ no \\
& $11.8 \%$ yes \\
& $88.2 \%$ no \\
& $9.6(S D \pm 6.7)$ \\
\hline & \\
\hline &
\end{tabular}

outcomes, $69.7 \%$ of the pre-frail older adults were considered to have functional decline in the physical domain. The average score on the Qmci screen was 65.1 $(\mathrm{SD} \pm 11.3)$. Based on their Qmci screen scores (Table 4), $31.0 \%$ of the participants were identified as having probable cognitive decline. Those participants experience especially problems with the task focusing on verbal fluency and logical memory. Finally, two instruments provided extra information on the nutritional domain. The average score on the extended version of the MNA was $26.7(\mathrm{SD} \pm 2.1)$ and none of the participants were classified as having malnutrition. However, only $32 \%$ of participants had a normal or healthy weight and $67 \%$ were overweight or obese. Table 5 provides an overview of the BMI and waist circumference scores. The average waist circumference was $101.3(\mathrm{SD} \pm 14.8)$. Based on the outcome of step two of the PERSSILAA screening $82.0 \%$ of pre-frail participants showed functional decline on at least one of the assessed domains.

\section{The merit of the PERSSILAA screening}

To investigate the merit of the PERSSILAA screening procedure over the use of a frailty scale in isolation, the classification (frail, pre-frail, robust) of the older adults based on the GFI alone and based on the PERSSILAA screening procedure were compared. Based on the GFI alone, only $8.2 \%(n=207)$ of the older adults were classified as pre-frail and $75 \%(n=2.823)$ as robust. This compares to the proportion identified after step one of the PERSSILAA screening (frail $=16.8 \%$; pre-frail $=20.6 \%$; robust $=62.3 \%)$ which differs significantly $\left(X^{2}=5003.6\right.$; $p<0.05)$

Of the 2823 older adults, classified as robust based on only the GFI alone, $16.6 \%(n=470)$ experienced impairment on at least one of the frailty subdomains. Only three older adults experienced impairment in all three domains, 46 experienced impairment in two domains (76.1\% in the physical and the cognitive domain; $19.6 \%$ in the physical and nutrition domain; and $4.3 \%$ in the cognitive and nutrition domain) and 421 experienced impairment in one domain $(56.7 \%$ in the physical domain; $39.7 \%$ in the cognitive domain; and 3.6 in the nutrition domain). Given these results, the PERSSILAA screening is better able to identify those older adults who experience functional decline and are at risk of becoming frail than the GFI alone.

\section{Discussion}

This paper presents the PERSSILAA screening pathway and the outcome of the baseline two-step screening and assessment. Identifying those at risk of developing frailty (i.e. pre-frailty) is important to prevent older adults

Table 3 Results of step one of the PERSSILAA screening showing mean scores and standard deviation

\begin{tabular}{|c|c|c|c|c|}
\hline & \multicolumn{4}{|l|}{ Group } \\
\hline & All older adults $(n=3764)$ & Robust $(n=2353)$ & Pre-frail $(n=777)$ & Frail $(n=634)$ \\
\hline \multicolumn{5}{|l|}{ Instrument } \\
\hline GFI & $2.2(\mathrm{SD} \pm 2.3)$ & $0.9(\mathrm{SD} \pm 1.0)$ & $2.7(\mathrm{SD} \pm 1.3)$ & $6.3(\mathrm{SD} \pm 1.5)$ \\
\hline PF10 & $\begin{array}{l}80.2(S D \pm 24.0) \\
19.7 \% \text { Functional decline }\end{array}$ & $92.0(\mathrm{SD} \pm 9.5)$ & $\begin{array}{l}64.7(S D \pm 25.5) \\
50.4 \% \text { Functional decline }\end{array}$ & $\begin{array}{l}55.8(\mathrm{SD} \pm 29.3) \\
55.0 \% \text { Functional decline }\end{array}$ \\
\hline AD8 & $\begin{array}{l}0.7(\mathrm{SD} \pm 1.2) \\
14.1 \% \text { Cognitive impairment }\end{array}$ & $0.2(S D \pm 0.4)$ & $\begin{array}{l}1.2(\mathrm{SD} \pm 1.3) \\
36.5 \% \text { Cognitive impairment }\end{array}$ & $\begin{array}{l}1.9(\mathrm{SD} \pm 1.9) \\
46.4 \% \text { Cognitive impairment }\end{array}$ \\
\hline MNA-SF & $\begin{array}{l}10.3(S D \pm 1.4) \\
5.2 \% \text { Malnutrition }\end{array}$ & $10.8(S D \pm 0.7)$ & $\begin{array}{l}10.2(S D \pm 1.3) \\
6.5 \% \text { Malnutrition }\end{array}$ & $\begin{array}{l}9.0(\mathrm{SD} \pm 2.2) \\
22.9 \% \text { Malnutrition }\end{array}$ \\
\hline
\end{tabular}


Table 4 Results of step two of the PERSSILAA baseline screening showing mean scores and standard deviation (SD)

\begin{tabular}{lll}
\hline & & Pre-frail $(n=623)$ \\
\hline Physical domain & Instrument & \\
& TUGT & $7.9 \mathrm{~s}(\mathrm{SD} \pm 3.1)$ \\
& CST & 12.3 times (SD \pm 4.4$)$ \\
& CSRT & $2.2 \mathrm{~cm}(\mathrm{SD} 6.9)$ \\
& 2MST & 123.9 times (SD \pm 52.0$)$ \\
Cognitive domain & Qmci screen - total score & $65.1(\mathrm{SD} \pm 11.3)$ \\
& Qmci - Orientation & $9.7(\mathrm{SD} \pm 0.7)$ \\
& Qmci - Registration & $4.5(\mathrm{SD} \pm 0.8)$ \\
& Qmci - Clock drawing & $13.6(\mathrm{SD} \pm 3.1)$ \\
& Qmci - Delayed recall & $13.7(\mathrm{SD} \pm 4.8)$ \\
& Qmci - Verbal fluency & $8.3(\mathrm{SD} \pm 3.4)$ \\
& Qmci - Logical memory & $15.4(\mathrm{SD} \pm 5.6)$ \\
& MNA & $26.7(\mathrm{SD} \pm 2.1)$ \\
& Waist circumference & $101.3(\mathrm{SD} \pm 14.8)$
\end{tabular}

developing functional decline and becoming frail [7, 8]. In total, among a sample of the older population in the east of the Netherlands, 20.6\% older adults appeared to be at risk of becoming frail, based on a large-scale deployment of the PERSSILAA screening procedure. These older adults mainly experienced impairments in the physical and cognitive subdomains and could benefit from effective interventions to reduce the level of frailty [6].

The prevalence of frailty varies enormously in Europe [37] and worldwide [38] and therefore it is difficult to compare our results (16.8\% frail, $20.6 \%$ pre-frail and $62.3 \%$ robust). A systematic review focusing on the prevalence of frailty in community-dwelling older adults presented an overall prevalence of frailty of 10.7 and 41.6\% of pre-frailty [38]. More recently, the EU-funded Joint Action on Frailty Prevention (ADVANTAGE) showed that the prevalence of frailty among communitydwellers in European countries varied between 12 and $16 \%$ depending on the definition of frailty adopted (physical phenotype versus other definitions, respectively) [39]. Our results are also in line with a more recent paper [40] where the following percentage were reported; $15.1 \%$ frail, $33.3 \%$ pre-frail and $51.4 \%$ robust in

Table 5 Results of step two of the PERSSILAA baseline screening showing the BMI classification and the waist circumference

\begin{tabular}{llll}
\hline BMI Classification & & Percentage & Waist circumference \\
\hline Underweight & $<18.5$ & $1 \%$ & $76.9 \mathrm{~cm} \mathrm{(SD} \pm 6.8)$ \\
Normal (healthy weight) & $18.5-25$ & $32 \%$ & $88.7 \mathrm{~cm}(\mathrm{SD} \pm 10.7)$ \\
Overweight & $25-30$ & $42 \%$ & $103.4 \mathrm{~cm}(\mathrm{SD} \pm 9.6)$ \\
Obese & $>30$ & $25 \%$ & $114.8 \mathrm{~cm}(\mathrm{SD} \pm 12.7)$ \\
\hline
\end{tabular}

a population-based sample of 542 community-dwelling older adults aged $\geq 65$ years living in a metropolitan area in Italy using the FRAIL scale.

The PERSSILAA screening focuses on identifying those older adults who are at risk of becoming frail. This is unique as most screening pathways focus on identifying those older adults who are already frail $[9,14]$. The PERSSILAA screening approach is easily applicable in daily clinical practice and identifies physical and cognitive decline as well as malnutrition. From literature we know that pre-frail older adults are more likely to transition back to a robust state than those who are frail [41], though there is insufficient evidence for this at population-level European countries [39]. It has to be proven yet which strategy (screening for pre-frailty or frailty) is more effective in order to reduce the burden of disability, dependence, institutionalization, morbidity and mortality that would be the aim of any frailty screening program.

The elements of pre-frailty of the PERSSILAA screening process are inconclusive and need to be revised. The approach of the PERSSILAA project was to go at least beyond the physical domain and by this first the cognitive and nutritional domain were also assessed during the first and second step of the PERSSILAA screening pathway. As social isolation and loneliness cause severe health problems, a questionnaire on the social domain, as the Loneliness Scale developed by De Jong Gierveld and colleagues [42], should be included in the screening protocol. In literature, both loneliness as social isolation are linked to numerous negative health outcomes [43] comparable to the negative health outcomes of smoking, obesity, lack of exercise and high blood pressure [44].

Given its simplicity, with an emphasis on self-screening using brief paper-based or online questionnaires, the PERSSILAA screening process is potentially useful for primary prevention to define those pre-frail older adults who will benefit most from intervention programmes to build reserve and delay or present frailty [6]. PERSSILAA screening can also support health planning and allocation of limited health and social care resources in the community. It is partially self-administrated and efficient as after the initial triage (step one) it selects out probable pre-frail older adults who are then invited for a face-to-face assessment (step two). The results of the PERSSILAA screening (step 1 and step 2) model were made available to participating municipalities [15] and these results could help them to allocate resources based on objective data. Further, while there is as yet insufficient data to support population-level screening for frailty [14], this study adds to the growing evidence for population-based two-step screening and assessment approaches [14]. 
Like any study, this one has some limitations. Considering the questionnaires, both the AD8 and MNA-SF are not validated in Dutch and therefore the reliability, validity and sensitivity of these questionnaires for the Dutch population are unknown. Besides, there is a potential for (self) selection bias limiting generalizability. Further, GPs excluded those considered 'too' frail, unwell or unsuitable to participate in the screening. Next to this, compared to the general Dutch population the number of high educated older adults seems to be overrepresented and this could have affected the overall response rate. In addition, the response rate was modest with approximately a third of those invited to voluntarily complete the PERSSILAA questionnaire and consenting to participate. This disappointing response rate could be due to the choice to send out the questionnaire via a mass mailing. To increase the response-rate the questionnaires could be to hand out by the GPs. During the participatory design process [15] GPs were not positive about this more practice-based strategy as not all older adults could be reach and handing out the questionnaires was perceived as a burden. The reasons for non-participation are unknown. However, for a subset of participants $(n=1228$, with a response rate of $30.6 \%)$, we asked the non-responders $(n=852)$ to return a postcard when they did not want to participate providing reasons of which 165 (19.4\%) postcards were received. These indicated that the main reason for not participating was that they saw no added value as they perceived themselves as being fit (33.3\%), or that they thought that participation was not applicable or appropriate from them, as they already received (extensive) medical care (24.2\%).

\section{Conclusions}

The PERSSILAA screening pathway outlined in this study is a unique screening process for the primary prevention of pre-frailty that could be utilized by municipalities and GPs to identify community-dwelling older adults who are at risk of becoming frail and to target those who will benefit most from programmes to strengthen their resources and minimize risk factors predisposing to the development of frailty. In addition, the PERSSILAA screening process provides municipalities with objective information to better allocate their resources and potentially support the monitoring and surveillance of frailty at national or transnational level. Further study is required to investigate if this approach could be used with suitable interventions to prevent frailty at population-level $[45,46]$, and to determine the societal impact of using the approach (the societal return on investment), including GPs' and patients' acceptance of the approach.

\section{Abbreviations}

2MST: Two-minute step test; AD8: AD8 Dementia Screening Interview; BMI: Body Mass Index; CSRT: Chair sit and reach test; CST: Chair stand test; GFI: Groningen Frailty Indicator; GP: General Practitioner; MCl: Mild cognitive impairment; MNA: Mini Nutrition Assessment; MNA-SF: Mini Nutrition Assessment Short-Form; n: Number; PERSSILAA: Personalised ICT Supported Service for Independent Living and Active Ageing; PF-10: SF-36 physical functioning scale; Qmci screen: Quick mild cognitive impairment screen; SD: Standard deviation; TUGT: Timed up and go test

\section{Acknowledgements}

The authors would like to acknowledge all older adults who joined the project and also all GPs, municipality officials and officers, welfare workers, physical therapist of the municipalities of Enschede, Hengelo, Tubbergen and Twenterand.

\section{Funding}

This work was funded by the European Union within the PERSSILAA project (FP7-ICT-610359). The funding body had no role in the design of the study and collection, analysis, and interpretation of data and in writing the manuscript.

\section{Availability of data and materials}

The datasets used and/or analyzed during the current study are available from the corresponding author on reasonable request.

\section{Authors' contributions}

$\mathrm{MVH}$ is the principal investigator of this study and obtained funding. SJK and LV have conceptualized and written the manuscript. SF was responsible for the coordination and execution of the PERSILAA screening. MDW, ROC have made substantial contributions to the content of the PERSSILAA screening. All authors have read and approved the final version of the manuscript.

\section{Ethics approval and consent to participate}

Considering to Dutch law (Medical Research Involving Human Subjects Act), the nature of this research did not require formal medical ethical approval. The appropriate ethics committee (Medisch Ethische Toetsingscommissie (METC) Twente) ruled that no formal ethics approval was required for this particular (reference K14-42). At the end of the questionnaire, older adults were asked whether they agreed to the use of their data for research purposes (informed consent), when they agreed they had to tick a checkbox.

Consent for publication

Not applicable.

\section{Competing interests}

The authors declare that they have no competing interests.

\section{Publisher's Note}

Springer Nature remains neutral with regard to jurisdictional claims in published maps and institutional affiliations.

\section{Author details \\ ${ }^{1}$ Roessingh Research and Development, Roessinghsbleekweg 33b, 7522, AL, Enschede, The Netherlands. ${ }^{2}$ University of Twente, Faculty of Electrical Engineering, Mathematics and Computer Science, Telemedicine group, Enschede, the Netherlands. ${ }^{3}$ ZiekenhuisGroep Twente (ZGT), scientific office ZGT academie, Almelo, the Netherlands. ${ }^{4}$ Centre for Gerontology and Rehabilitation, University College Cork, Cork City, Ireland. ${ }^{5}$ Clinical Sciences Institute, National University of Ireland Galway, Galway City, Ireland.}

Received: 18 September 2018 Accepted: 22 April 2019

Published online: 03 May 2019

\section{References}

1. World Health Organization. World report on ageing and health. Luxembourg; 2015.

2. Rockwood K, Hogan DB, MacKnight C. Conceptualisation and measurement of frailty in elderly people. Drugs Aging. 2000;17(4):295-302. 
3. Abellan van Kan G, Rolland Y, Bergman H, Morley JE, Kritchevsky SB, Vellas B. The I.A.N.A Task Force on frailty assessment of older people in clinical practice. J Nutr Health Aging. 2008;12(1):29-37.

4. Apostolo J, Cooke R, Bobrowicz-Campos E, Santana S, Marcucci M, Cano A Vollenbroek-Hutten M, Germini F, Holland C. Predicting risk and outcomes for frail older adults: an umbrella review of frailty screening tools. JB Database System Rev Implement Rep. 2017;15(4):1154-208.

5. Vellas B, Sourdet S. Prevention of frailty in aging. J Frailty Aging. 2017;6(4): 174-7.

6. Puts MTE, Toubasi S, Andrew MK, Ashe MC, Ploeg J, Atkinson E, Ayala AP, Roy A, Rodríguez Monforte $\mathrm{M}$, Bergman $\mathrm{H}$, et al. Interventions to prevent or reduce the level of frailty in community-dwelling older adults: a scoping review of the literature and international policies. Age Ageing. 2017;46(3):383-92.

7. Heuberger RA. The frailty syndrome: a comprehensive review. J Nutr Gerontol Geriatr. 2011;30(4):315-68.

8. van Oostrom SH, van der AD, Rietman ML, Picavet HSJ, Lette M, Verschuren WMM, de Bruin SR, Spijkerman AMW. A four-domain approach of frailty explored in the Doetinchem cohort study. BMC Geriatr. 2017;17(1):196.

9. Bruyere O, Buckinx F, Beaudart C, Reginster JY, Bauer J, Cederholm T, Cherubini A, Cooper C, Cruz-Jentoft AJ, Landi F, et al. How clinical practitioners assess frailty in their daily practice: an international survey. Aging Clin Exp Res. 2017;29(5):905-12.

10. Gilardi F, Capanna A, Ferraro M, Scarcella P, Marazzi MC, Palombi L, Liotta G. Frailty screening and assessment tools: a review of characteristics and use in public health. Annali di igiene : medicina preventiva e di comunita. 2018; 30(2):128-39.

11. Laksmi PW. Challenges in screening and diagnosing frailty syndrome: which tool to be used? Acta Medica Indonesiana. 2015:47(3):181-2.

12. O'Caoimh R, Cornally N, Weathers E, O'Sullivan R, Fitzgerald C, Orfila F, Clarnette R, Paul C, Molloy DW. Risk prediction in the community: a systematic review of case-finding instruments that predict adverse healthcare outcomes in community-dwelling older adults. Maturitas. 2015;82(1):3-21.

13. Bongue B, Buisson A, Dupre C, Beland F, Gonthier R, Crawford-Achour E. Predictive performance of four frailty screening tools in communitydwelling elderly. BMC Geriatr. 2017;17(1):262.

14. Rodriguez-Laso A, O'Caoimh R, Galluzzo L, Carcaillon-Bentata L, Beltzer N, Macijauskiene J, Albaina Bacaicoa O, Ciutan M, Hendry A, Lopez-Samaniego $L$, et al. Population screening, monitoring and surveillance for frailty: three systematic reviews and a grey literature review. Annali dell'Istituto superiore di sanita. 2018:54(3):253-62.

15. van Velsen L, Illario M, Jansen-Kosterink S, Crola C, Di Somma C, Colao A Vollenbroek-Hutten M. A community-based, technology-supported health service for detecting and preventing frailty among older adults: a participatory design development process. J Aging Res. 2015;2015:9.

16. Gomez MI, García-Sánchez I, Carta A, Antunes JP. A Collection of Good Practices That Support the Prevention and Early Diagnosis of Frailty and Functional Decline, Both Physically and Cognitive, in Older People. Brussels, Belgium: European Commission; 2013.

17. Fanning J, McAuley E. A comparison of tablet computer and paper-based questionnaires in healthy aging research. JMIR Res Protoc. 2014;3(3):e38.

18. van Velsen L, Frazer S, N'Dja A, Ammour N, Del Signore S, Zia G, Hermens H. The reliability of using tablet Technology for Screening the health of older adults. Stud Health Technol Inform. 2018;247:651-5.

19. Beukema S, van Velsen L, Jansen-Kosterink S, Karreman J. "There Is Something We Need to Tell You...": Communicating Health-Screening Results to Older Adults via the Internet. Telemed J E Health. 2017;23(9):741-6.

20. Peters $L L$, Boter $H$, Buskens E, Slaets JP. Measurement properties of the Groningen frailty Indicator in home-dwelling and institutionalized elderly people. J Am Med Dir Assoc. 2012;13(6):546-51.

21. Steverink N, Slaets JPJ, Schuurmans H, Lis M. Measuring frailty: development and testing of the Groningen Frailty Indicator (GFI). Gerontologist. 2001; 41(special issue 1):236-7.

22. Stewart AL, Hays RD, Ware JE Jr. The MOS short-form general health survey. Reliability and validity in a patient population. Med Care. 1988;26(7):724-35.

23. VanderZee Kl, Sanderman R, Heyink J. A comparison of two multidimensional measures of health status: the Nottingham health profile and the RAND 36-item health survey 1.0. Qual Life Res. 1996;5(1):165-74.

24. Aaronson NK, Muller M, Cohen PD, Essink-Bot ML, Fekkes M, Sanderman R, Sprangers MA, te Velde A, Verrips E. Translation, validation, and norming of the Dutch language version of the SF-36 health survey in community and chronic disease populations. J Clin Epidemiol. 1998;51(11):1055-68.
25. Galvin JE, Roe CM, Coats MA, Morris JC. Patient's rating of cognitive ability: using the AD8, a brief informant interview, as a self-rating tool to detect dementia. Arch Neurol. 2007;64(5):725-30.

26. Galvin JE, Roe CM, Powlishta KK, Coats MA, Muich SJ, Grant E, Miller JP, Storandt M, Morris JC. The AD8: a brief informant interview to detect dementia. Neurology. 2005;65(4):559-64.

27. Rubenstein LZ, Harker JO, Salva A, Guigoz Y, Vellas B. Screening for undernutrition in geriatric practice: developing the short-form mininutritional assessment (MNA-SF). J Gerontol A Biol Sci Med Sci. 2001;56(6): M366-72.

28. Kaiser MJ, Bauer JM, Ramsch C, Uter W, Guigoz Y, Cederholm T, Thomas DR, Anthony $\mathrm{P}$, Charlton KE, Maggio M, et al. Validation of the mini nutritional assessment short-form (MNA-SF): a practical tool for identification of nutritional status. J Nutr Health Aging. 2009;13(9):782-8.

29. Morris S, Morris ME, lansek R. Reliability of measurements obtained with the timed "up \& go" test in people with Parkinson disease. Phys Ther. 2001; 81(2):810-8.

30. Jones CJ, Rikli RE, Beam WC. A 30-s chair-stand test as a measure of lower body strength in community-residing older adults. Res Q Exerc Sport. 1999; 70(2):113-9.

31. Różańska-Kirschke $A$, Kocur $P$, Wilk M, Dylewicz $P$. The Fullerton fitness test as an index of fitness in the elderly. Medical Rehabilitation. 2006;10(2):9-16.

32. Rikli RE, Jones CJ. Functional fitness normative scores for communityresiding older adults, ages 60-94. J Aging Phys Act. 1999;7(2):162-81.

33. O'Caoimh R, Gao Y, McGlade C, Healy L, Gallagher P, Timmons S, Molloy DW. Comparison of the quick mild cognitive impairment (Qmci) screen and the SMMSE in screening for mild cognitive impairment. Age Ageing. 2012; 41(5):624-9.

34. O'Caoimh R, Gao Y, Gallagher PF, Eustace J, McGlade C, Molloy DW. Which part of the quick mild cognitive impairment screen (Qmci) discriminates between normal cognition, mild cognitive impairment and dementia? Age Ageing. 2013;42(3):324-30.

35. Bunt $S, O^{\prime}$ Caoimh R, Krijnen WP, Molloy DW, Goodijk GP, van der Schans CP Hobbelen HJSM. Validation of the Dutch version of the quick mild cognitive impairment screen (Qmci-D). BMC Geriatr. 2015;15(1):115.

36. O'Caoimh R, Gao Y, Svendovski A, Gallagher P, Eustace J, Molloy DW. Comparing approaches to optimize cut-off scores for short cognitive screening instruments in mild cognitive impairment and dementia. J Alzheimers Dis. 2017;57(1):123-33.

37. O'Caoimh R, Galluzzo L, Rodriguez-Laso A, Van der Heyden J, Ranhoff AH, Lamprini-Koula M, Ciutan M, Lopez-Samaniego L, Carcaillon-Bentata L, Kennelly $S$, et al. Prevalence of frailty at population level in European ADVANTAGE joint action member states: a systematic review and metaanalysis. Annali dell'Istituto superiore di sanita. 2018:54(3):226-38.

38. Collard RM, Boter H, Schoevers RA, Oude Voshaar RC. Prevalence of frailty in community-dwelling older persons: a systematic review. J Am Geriatr Soc. 2012;60(8):1487-92

39. O'Caoimh R, Galluzzo L, Rodriguez-Laso A, Van der Heyden J, Ranhoff AH, Carcaillon-Bentata L, Beltzer N, Kennelly S, Liew A. Transitions and trajectories in frailty states over time: a systematic review of the European joint action ADVANTAGE. Annali dell'Istituto superiore di sanita. 2018:54(3): 246-52.

40. Poli S, Cella A, Puntoni M, Musacchio C, Pomata M, Torriglia D, Vello N, Molinari B, Pandolfini $\mathrm{V}$, Torrigiani $\mathrm{C}$, et al. Frailty is associated with socioeconomic and lifestyle factors in community-dwelling older subjects. Aging Clin Exp Res. 2017;29(4):721-8.

41. Gill TM, Gahbauer EA, Allore HG, Han L. Transitions between frailty states among community-living older persons. Arch Intern Med. 2006; 166(4):418-23.

42. De Jong GJ, Van Tilburg T. The De Jong Gierveld short scales for emotional and social loneliness: tested on data from 7 countries in the UN generations and gender surveys. Eur J Ageing. 2010;7(2):121-30.

43. Leigh-Hunt N, Bagguley D, Bash K, Turner V, Turnbull S, Valtorta N, Caan W. An overview of systematic reviews on the public health consequences of social isolation and loneliness. Public Health. 2017;152:157-71.

44. Cacioppo JT, Hawkley LC, Norman GJ, Berntson GG. Social isolation. Ann N Y Acad Sci. 2011;1231(1):17-22.

45. O'Caoimh R, Molloy DW, Fitzgerald C, Van Velsen L, Cabrita M, Nassabi MH, de Vette F, van Weering MD, Jansen-Kosterink S, Kenter W, et al. ICTSupported Interventions Targeting Pre-frailty: Healthcare Recommendations from the Personalised ICT Supported Service for Independent Living and 
Active Ageing (PERSSILAA) Study. In: Information and Communication Technologies for Ageing Well and e-Health: 2018//. Cham: Springer International Publishing; 2018. p. 69-92.

46. Frost R, Belk C, Jovicic A, Ricciardi F, Kharicha K, Gardner B, lliffe S, Goodman

C, Manthorpe J, Drennan VM, et al. Health promotion interventions for community-dwelling older people with mild or pre-frailty: a systematic review and meta-analysis. BMC Geriatr. 2017;17(1):157.

Ready to submit your research? Choose BMC and benefit from:

- fast, convenient online submission

- thorough peer review by experienced researchers in your field

- rapid publication on acceptance

- support for research data, including large and complex data types

- gold Open Access which fosters wider collaboration and increased citations

- maximum visibility for your research: over $100 \mathrm{M}$ website views per year

At $B M C$, research is always in progress.

Learn more biomedcentral.com/submissions 